Clean $2^{\text {nd }}$ revised version submitted to Autonomic Neuroscience

\title{
SQUATTING TEST : A POSTURE TO STUDY AND COUNTERACT CARDIOVASCULAR ABNORMALITIES ASSOCIATED WITH AUTONOMIC DYSFUNCTION
}

Jean-Christophe Philips , André J. Scheen

University of Liège, Division of Diabetes, Nutrition and Metabolic Disorders, Department of Medicine, CHU Liège, Sart Tilman, B-4000 Liège, Belgium

Address for correspondence :

\author{
Pr André J. SCHEEN \\ Department of Medicine \\ CHU Sart Tilman (B35) \\ B-4000 LIEGE 1 \\ BELGIUM \\ Phone : 32-4-3667238 \\ FAX : 32-4-3667068 \\ Email : andre.scheen@ chu.ulg.ac.be
}

Short title : Squatting test and autonomic dysfunction

Text + references word count $=3830($ instead of 4424$)$ words

Abstract word count $=225$ words 


\section{SUMMARY}

The squatting test is an active posture manoeuvre that imposes one of the most potent orthostatic stresses. In normal subjects, the changes in blood pressure and heart rate are transient because of appropriate baroreflex homeostasis and do not provoke symptoms. However, in various pathological conditions, both the increase in blood pressure during squatting and the decrease in blood pressure during standing may be more important and sustained, potentially leading to complaints and adverse events. Squatting has been used to evaluate patients with tetralogy of Fallot, heart transplant, dysautonomia, including diabetic cardiovascular autonomic neuropathy, and individuals prone to vasovagal syncope. Careful analysis of changes in blood pressure and heart rate during the transition from standing to squatting and from squatting to standing allows the early detection of altered vagal and/or sympathetic function. Of note squatting position has been proposed as a therapeutic mean to counteract the fall in blood pressure in patients suffering from dizziness due to dysautonomia and orthostatic hypotension or presenting pre-syncope symptoms, such as soon after exercise. The aims of the present review are to analyse the haemodynamic pattern during a squatting test in various pathological situations and to describe what may be the negative and positive haemodynamic changes associated with this posture. We were especially interested in using the squatting test for the assessment of cardiovascular autonomic neuropathy associated with diabetes mellitus.

Key-words : Blood pressure - Cardiovascular autonomic neuropathy - Diabetes Dysautonomia - Heart rate - Orthostatic hypotension - Squatting - Syncope 


\section{INTRODUCTION}

In normal subjects, blood pressure (BP) is tightly regulated and the variations are generally of small amplitude and/or of short duration despite acute postural changes, including the squatting to standing manoeuvre that represents the most potent orthostatic stress (Scheen et al., 1990). However, several pathological entities may be associated with autonomic disorders and dysregulation of BP homeostasis leading to orthostatic hypotension and syncope as most obvious adverse events (Wieling et al., 2007; Freeman 2008; Medow et al., 2008). Orthostatic hypotension has been shown to be associated with an increased risk of cardiovascular morbidity and all-cause mortality in the general population (Fedorowski et al., 2010) and in diabetic patients (Maser et al., 2003). Other orthostatic syndromes are also quite frequent such as postural tachycardia and syncope, and appear to be different from classical orthostatic hypotension (Raj, 2010). Laboratories able to test autonomic function are increasingly available and rely on batteries of well-accepted, noninvasive tests among which tests of parasympathetic cardiovagal heart rate (HR) variability and sympathetic vasoconstriction are most commonly employed (Weimer, 2010).

Non-invasive continuous monitoring of systolic and diastolic BP together with HR has greatly facilitated the study of haemodynamic changes during dynamic tests (Rossberg \& Penaz, 1988; Imholz et al., 1998; Imholz et al., 1990). Various posture tests are classically used to assess haemodynamic orthostatic adaptation and autonomic function. The most popular posture test used in clinical research is the passive head-up tilt table test at $70^{\circ}$ (Grubb \& Kosinski, 1997; Madden et al., 2008). Another active manoeuvre, the so-called squatting test, produces the strongest acute orthostatic stress when the subject stands up (Scheen et al., 1990; Marfella et al, 1994a). Careful analysis of BP and HR changes during both transition states, from standing to squatting and from squatting to standing, respectively, provides interesting information as far as performance of baroreflexes and haemodynamic homeostasis are concerned (Rossberg \& Penaz, 1988). For instance, the analysis of HR and BP changes occurring during a squatting test has been used by our group to assess orthostatic hypotension (Scheen et al., 1990), cardiovascular autonomic neuropathy (CAN) (Philips et al., 2009) and pulsatile stress (Philips et al., 2008); Philips et al., 2010a; Philips et al., 2010b) in patients with type 1 diabetes mellitus. Furthermore, squatting position is a long recognized therapeutic manoeuvre that can improve haemodynamics in patients with some congenital cardiac diseases (tetralogy of Fallot) (Lurie, 1953; Guntheroth et al., 1968). More recently, squatting 
has also been proposed as a therapeutic manoeuvre to counteract BP fall in individuals suffering from orthostatic hypotension (van Lieshout et al., 1992), a frequent complication of autonomic failure, or vasovagal syncope (Krediet et al., 2008).

The present review will first present a brief description of the haemodynamic changes occurring during the standing-squatting-standing transition phases in normal subjects. Afterwards we will analyze the postural changes in patients with autonomic failure, including diabetic CAN, in order to better understand the adverse events but also the positive haemodynamic changes that are reported with this squatting posture. In all instances, it is important to separate haemodynamic changes occurring from standing to squatting (Table 1) from those observed during the transition from squatting to standing in patients with cardiovascular disease and/or autonomic dysfunction (Table 2).

\section{Physiology of the standing-squatting-standing test}

In healthy subjects, the transition from standing to squatting is accompanied by complex haemodynamic changes (Rickards \& Newman, 2003). An initial burst in systolic, diastolic and mean arterial BP, a rise in pulse pressure (PP) and a brief peak in heart rate (HR) are systematically detected (Figure 1). After a few seconds there is a trend to return to baseline values for all parameters followed by a more sustained rise in systolic, diastolic and mean BP and in PP levels. This increase in BP is associated with a reduction in HR. The bradycardia is secondary to baroreceptor activity and is abolished by atropine (Marfella et al., 1994b). Squatting augments cardiac output (CO) by increasing venous return secondary to muscular pumping in the legs. The kinking of femoral arteries, which might increase peripheral resistance, does not seem to play a major role. Thus increased preload by augmentation of venous return rather than increased systemic vascular resistance mainly explains the rise in BP. This may contribute to the greater increase of systolic BP compared to diastolic BP, and thus the augmentation of pulse pressure in squatting position.

The squat-stand transition induces profound haemodynamic changes (Rossberg \& Penaz, 1988, Smith et al., 1994). When normal subjects stand up, systolic BP, diastolic BP, and PP invariably fall. After 8 to 10 beats the BP starts to rise to its original level. The immediate cardiac response is characterized by a prompt rise in HR, which peaks at about 8 to 15 seconds and then tapers (Figure 1). Propranolol, a beta-adrenergic blocking agent, markedly attenuates reflex tachycardia (Marfella et al., 1994a). At standing from squatting the total vascular resistance decreases sharply at 5 to 10 seconds, which explains the abrupt fall in $\mathrm{BP}$, followed by a rapid rebound and overshoot. Over the first 30 seconds there is a steady 
parallel decline of thoracic blood volume, stroke volume and CO (after an initial surge).

During the stabilized response (30 seconds to 20 minutes), the haemodynamic variables are relatively steady, showing average increases in HR of about 15 to $30 \%$ and in total vascular resistance of 30 to $40 \%$, with only modest changes in BP values. Thus, after squatting, the upright posture results in profound haemodynamic changes, most occurring during the first 30 seconds (Figure 1).

\section{Clinical applications}

\section{1) Cyanotic patients with cardiac malformations}

William Hunter noted in 1784 that cyanotic patients obtained relief from faintness by assuming the posture that we now call "squatting" (Hunter, 1784). The tetralogy of Fallot is the most common form of cyanotic congenital heart diseases (Apitz et al., 2009). Children with the tetralogy of Fallot soon discovered the symptomatic relief obtained by squatting after exercise (Lurie, 1953). Several explanations have been proposed for this observation. The rise in systemic vascular resistance that occurs during squatting was proposed to be responsible for increasing the relative flow into the pulmonary artery (Hamilton et al., 1950). The kneechest position adopted during squatting after exercise has been shown to be accompanied by a rise in systemic arterial BP and a rise in arterial oxygen saturation, which had fallen to low levels during exercise (Guntheroth et al., 1968). Because squatting impedes the venous return from the legs, it has been proposed that it minimizes the tendency of the arterial oxygen saturation to fall with exercise (Brotmacher, 1957). From all available data, it may be concluded that the beneficial effect of squatting in patients with tetralogy of Fallot is mainly due to two mechanisms : on the one hand, the exclusion from the circulation of the highly unsaturated blood from the legs, due to the compression of the femoral veins; on the other hand, the reduction in the degree of right-to-left shunting due to the increase of peripheral vascular resistance, resulting in a favourable increase of the blood flow to the lungs.

A recent study measured the difference in transcutaneous pulse oxygen saturation between the standing position and squatting position in patients with tetralogy of Fallot (Li et al., 2009). The mean pulse oxygen saturation was $79 \%$ in standing patients and $84 \%$ in squatting patients (significant mean difference of 5\%). The authors proposed this difference in pulse oxygen saturation to be used as a supplement to echocardiography and cardiac catheter in evaluating tetralogy of Fallot before surgery.

\section{2) Patients with heart transplant}


To determine the role of cardiac autonomic innervation in the mediation of cardiovascular responses, haemodynamic patterns were examined in nine normal men and six heart transplant recipients during 2 min of squatting (Hanson et al., 1995). As compared to normal individuals, heart transplant recipients exhibited similar increases in stroke volume index monitored by thoracic impedance cardiography and mean arterial BP $(+8.5$ versus +5.0 $\mathrm{mmHg}$ ), which were sustained throughout squatting. Each group also showed an initial decrease in peripheral resistance followed by a return to baseline values after 20 seconds. HR decreased in normal individuals (- 10 beats/min) but was unchanged or minimally increased $(+2$ beats/min) in heart transplant recipients, in agreement with cardiac denervation. Forearm vascular resistance was conspicuously decreased in normal individuals (- 47.8 units) but more modestly (- 20.9 units) in heart transplant recipients. Thus, the major haemodynamic responses to squatting (increased cardiac output and BP) are similar in normal individuals and heart transplant recipients (Figure 2). As already discussed, these responses are primarily due to augmented venous return and are not altered by cardiac denervation. Both groups also exhibited a transient decline in peripheral vascular resistance which is most likely mediated by arterial baroreflexes activated by the acute rise in arterial BP.

\section{3) Patients with autonomic failure and orthostatic hypotension}

Orthostatic hypotension is the most disabling and serious manifestation of adrenergic failure (Wieling et al., 2007; Freeman, 2008; Medow et al., 2008). Upright posture requires rapid and effective circulatory and neurologic compensations to maintain BP and consciousness. There is a broad, heterogeneous group of disturbances in the autonomic nervous system, each of which is manifested by hypotension, orthostatic intolerance, and syncope. Haemodynamic assessment using head-up tilt with determination of cardiopulmonary volume and systemic vascular resistance differentiated between venous pooling and autonomic insufficiency in these patients (Schutzman et al., 1994). In patients with chronic orthostatic intolerance (postural tachycardia syndrome), blunted arterial vasoconstriction produces passive redistribution of blood within peripheral venous capacitance beds, while venous compliance is similar to that of control subjects (Stewart, 2002). This contrasts with patients with neurocardiogenic syncope (see below), who are characterized by normal peripheral vascular physiology (Stewart \& Weldon, 2003).

Drug treatment of orthostatic hypotension needs to be combined with nonpharmacological approaches, such as compression of venous capacitance beds and use of physical counter-manoeuvres (Low \& Singer, 2008). Indeed denervation increases vascular 
capacity, and venous compression improves orthostatic hypotension by reducing this capacity and increasing peripheral resistance index. A reduction in venous capacity, secondary to some physical counter manoeuvres (e.g., squatting or leg crossing), or the use of compressive garments, can ameliorate orthostatic hypotension. Compression of all compartments is the most efficacious, followed by abdominal compression, whereas leg compression alone was less effective, presumably reflecting the large capacity of the abdomen relative to the legs (Denq et al., 1997). Another study confirms that in patients with neurogenic orthostatic hypotension, abdominal compression (somewhat mimicking that occurring during squatting) increases standing BP to a varying degree by increasing stroke volume (Smit et al., 2004). Thus, various physical manoeuvres, among which is squatting posture, can reduce postural hypotension in autonomic failure (Wieling et al., 1993). Of note squatting has been recommended by the European Federation of the Neurological Societies among the physical measures for the management of patients with orthostatic hypotension (Lahrmann et al., 2006).

Haemodynamic changes associated with orthostatic hypotension in one patient with pure progressive autonomic failure were studied by a passive head-up $70^{\circ}$ tilt manoeuvre and an active squatting test (Titianova et al., 1997). Stand-up tilting induced slight decrease in mean BP and mean blood flow velocity during transcranial Doppler sonography monitoring of the right middle cerebral artery, without changes in HR. Changes of systemic haemodynamics occurred during the first minute of passive standing and they increased within the first hour; however, the cerebral haemodynamics remained relatively stable. Active standing from squatting was accompanied by a more severe decrease in the mean BP and the mean cerebral blood flow velocity, and an increase in vascular resistance immediately after the upright position. The haemodynamic changes were not followed by a secondary cardiac acceleration; they increased within the first minute of active standing and evoked a syncope. During squatting as a self-selected preventive mechanism in this patient an increase in mean BP and mean cerebral blood flow velocity occurred.

Squatting-induced BP changes were studied in 7 patients with hypoadrenergic orthostatic hypotension and in 6 healthy subjects. Squatting was associated with marked increase in mean BP of $44 \mathrm{mmHg}$ compared with only $8 \mathrm{mmHg}$ in healthy controls. Patients with orthostatic intolerance should be told about this BP-raising manoeuvre in order combat orthostatic dizziness (van Lieshout et al., 1992). The effectiveness of squatting has been tested in patients with familial dysautonomia who frequently experience debilitating orthostatic hypotension (Tutaj et al., 2006). Squatting was compared to other countermanoeuvres 
(bending forward, abdominal compression, leg-crossing). All these manoeuvres were initiated after standing up, when systolic BP had fallen by $40 \mathrm{mmHg}$ or diastolic BP by $30 \mathrm{mmHg}$ or presyncope had occurred. During active standing, BP and total peripheral resistance decreased, calf volume increased but CO remained stable. Squatting induced significant increases in mean $\mathrm{BP}(+50.8 \mathrm{mmHg})$, andCO $(+18 \%)$, and total peripheral resistance $(+37$ $\%$, without significant change in HR. Squatting has the greatest effect on orthostatic BP in such patients and was the only countermanoeuvre capable of significantly increasing total peripheral resistance (Figure 3).

\section{4) Patients with vasovagal syncope}

Neurocardiogenic syncope is a rather complex phenomenon, which implicates several reflex mechanisms, especially the Bezold-Jarisch reflex (Somers \& Abboud, 1996). There is evidence that left ventricular mechanoreceptors may not be the exclusive afferent trigger for syncope and that central mechanisms may be implicated. Autonomic and particularly sympathetic mechanisms play a central role in the pathophysiology of vasovagal syncope (Morillo et al., 1997). Patients with orthostatic vasovagal reactions have impaired vagal baroreflex responses to BP changes below resting levels but normal initial responses to upright tilt. Even if subtle vasovagal physiological changes begin before overt presyncope, the final trigger of human orthostatic vasovagal reactions appears to be the abrupt disappearance of muscle sympathetic nerve activity (Morillo et al., 1997). Furthermore, baroreceptor gain, assessed by administering bolus injections of nitroprusside and phenylephrine, was shown to be significantly reduced in patients with carotid sinus hypersensitivity and a history of recurrent unexplained syncope (Morillo et al., 1999).

Nonpharmacological treatment has been proposed for reflex syncope (Wieling et al., 2004), as it was the case for orthostatic hypotension (Wieling et al., 1993). Leg crossing, muscle tensing, squatting, and the crash position are effective against vasovagal reactions through increases in CO (Krediet et al., 2005a). A Japanese study investigated haemodynamic changes during squatting in patients with a positive or a negative head-up tilt test to evaluate syncope (Kim et al., 2005). Squatting significantly and similarly increased systolic BP and diastolic BP in the two groups $(+7.1 /+4.6 \mathrm{mmHg}$ versus $+7.8 /+4.3 \mathrm{mmHg})$. Of note, in the same study, squatting aborted syncope in 7 of 8 patients.

If squatting is a potent physical manoeuvre to prevent syncope, a major drawback is that standing up from squatting is a large haemodynamic stressor, which often causes new presyncopal symptoms. Nevertheless lower body skeletal muscle tensing attenuates the 
decrease of mean arterial BP upon standing from squatting when used as a manoeuvre to prevent vasovagal syncope. This hypothesis has been confirmed experimentally (Krediet et al., 2007). After standing up from squatting mean BP decreased to a nadir of $64 \mathrm{mmHg}$, related to a reduction in $\mathrm{CO}$ ( $73 \%$ of supine values). Standing up with lower body skeletal muscle tensing limited the reduction in $\mathrm{CO}(85 \%)$ and mean BP nadir $(76 \mathrm{mmHg})$ with fewer or no presyncopal symptoms. Standing up from squatting with and without lower body skeletal muscle tensing did not affect total peripheral resistance (99\% versus $101 \%)$. Thus, squatting may be optimized as a physical manoeuvre to prevent vasovagal syncope; lower body skeletal muscle tensing is proposed as an effective follow-up manoeuvre to squatting when applied to prevent syncope.

Orthostatic tolerance is reduced following prolonged exercise and post-exercise syncope episodes are common (Murrell et al., 2009). One simple way to minimize this phenomenon is to adopt the squatting position at the end of the effort, in order to increase BP, a posture spontaneously adopted by many athletes after a run. The therapeutic value of squatting to prevent loss of consciousness in exercise-related vasovagal syncope has been illustrated in a young woman who had one episode of transient loss of consciousness and several of near-unconsciousness during exercise (Krediet et al., 2005b).

\section{5) Diabetic patients with cardiovascular autonomic neuropathy (CAN)}

CAN is a common complication in diabetes mellitus and is considered as an independent risk factor of cardiovascular mortality (Maser et al., 2003).

The HR responses observed after both squatting (bradycardia abolished by atropine) and standing (tachycardia attenuated by propranolol) are of reflex nature and may be useful to assess the functional integrity of, respectively, parasympathetic and sympathetic nerves in diabetes (Marfella et al., 1994b). SqTv index (Squatting Test vagal index, reflecting squatting-induced bradycardia) and SqTs index (Squatting Test sympathetic index, reflecting standing-induced reflex tachycardia) were calculated in a large cohort of healthy subjects and diabetic patients. Normal ranges for healthy subjects between 20-74 years showed a statistically significant negative correlation with age. Age and duration of diabetes had a negative influence on both SqT ratios. In the same study SqT ratios were compared with other reflex tests currently used for diagnosis of CAN : deep breathing, lying-to-standing, Valsalva manoeuvre, and BP change after standing (orthostatic hypotension). The conclusion was that SqT ratios can discriminate between healthy subjects and diabetic patients to an equal or 
greater extent than the other tests but are better than other single tests in identifying mild autonomic involvement.

By comparing changes in HR and finger arterial BP during three postural tests (lying-tostanding, sitting-to-standing, and squatting test), a significantly greater BP drop occurred in type 2 diabetic patients with CAN (defined by the presence of a pathological deep-breathing value) compared with patients without CAN or normal subjects during the squatting test, but not during the two other postural tests (Marfella et al., 1994a). The conclusion was that the intrinsic orthostatic load of the squatting test, which is greater than conventional postural manoeuvres (Scheen et al., 1990), makes the squatting test an easy and useful test to detect early orthostatic dysregulation in diabetes.

In a recent Japanese study, the differences between basal HR and HR during squatting, on the one hand, and between HR during standing and HR during squatting, on the other hand) correlated well with baroreflex sensitivity measured using the phenylephrine method in diabetic patients $(\mathrm{r}=0.66, \mathrm{P}<0.0001$ and $\mathrm{r}=0.61, \mathrm{P}<0.0001$, respectively) (Nakagawa et al., 2008). According to the authors, these squatting test indices provide useful information for assessing CAN and for identifying diabetic patients at high risk of cardiovascular events.

In a cross-sectional controlled study, we evaluated 159 patients with type 1 diabetes mellitus during a 3-min posture test (standing-squatting-standing) with continuous measurement of BP and HR by a Finapres ${ }^{\circledR}$ device (Philips et al., 2009). CAN was assessed by the E/I RR ratio during deep breathing and by three indices measured during the squatting test : SqTv and SqTs indices according to Marfella et al (Marfella et al., 1994a and 1994b) and the baroreflex gain assessed by plotting RR intervals according to systolic BP during the transition from squatting to standing, as previously reported (Philips et al., 2009). RR E/I ratio $(p<0.0001)$ and baroreflex gain $(p<0.0005)$ progressively decreased with diabetes duration. The parasympathetic index SqTv significantly increased $(\mathrm{p}<0.0001)$ whereas the sympathetic index SqTs only tended to decrease $(\mathrm{p}=0.12)$ according to diabetes duration. No such changes in CAN indices were observed in the age-matched non-diabetic population. Classically, parasympathetic dysfunction precedes sympathetic dysfunction. In agreement with this observation, SqTv index was markedly and significantly affected by diabetes duration whereas changes in SqTs did not reach the level of statistical significance in our population with T1DM. However, both SqTv and SqTs indices were significantly altered in diabetes when comparing patients with long duration T1DM and age-matched healthy controls (Philips et al., 2009; Philips et al., 2010b). 
In a recent study (unpublished results), we compared the haemodynamic changes during an active orthostatic test in 20 type 1 diabetic patients with low RR E/I ratio during a deep breathing test (used as marker of CAN) and in 40 matched healthy subjects. Compared with controls, diabetic patients had lower RR E/I ratio (1.05 versus $1.29, \mathrm{P}<0.00001$ ), higher HR values throughout the test ( 90 versus 82 beats. $\min ^{-1}, \mathrm{P}=0.0252$ ), greater squattinginduced PP rise $(+13$ versus $+7 \mathrm{mmHg}, \mathrm{P}=0.0063)$, and reduced reflex tachycardia $(+18$ versus +32 beats. $\left.\min ^{-1}, \mathrm{P}=0.0004\right)$ combined with a delayed return to baseline BP after standing (33 versus $21 \mathrm{sec}, \mathrm{P}=0.0167$ ) (Figure 4). Consequently, diabetic patients with CAN had both markedly reduced baroreflex gain (1.39 versus $\left.3.90 \mathrm{msec} . \mathrm{mm} \mathrm{Hg}^{-1}, \mathrm{P}=0.0001\right)$ and

elevated pulsatile stress (pulse pressure x HR) (4947 versus $4303 \mathrm{~mm} \mathrm{Hg.m^{-1 }}{ }^{-1} \mathrm{P}=0.00443$ ), especially in squatting position (Philips et al., 2008). SqTs was significantly reduced in type 1 diabetic patients $(1.10$ versus $1.22, \mathrm{P}=0.0001)$ whereas the trend to altered $\mathrm{SqT}$ v did not reach statistical significance in this group of patients.

Finally, we also reported in a large cohort of 159 patients with type 1 diabetes that squatting is associated with a greater increase in BP and pulse pressure according to diabetes duration (especially after 20 years of disease duration) and age than in non-diabetic controls, a finding that was attributed to accelerated arterial stiffness resulting from chronic hyperglycaemia (Philips et al., 2008; Philips et al., 2009). Whether this increase in BP and pulse pressure during squatting may exaggerate cardiovascular risk is unknown. It is noteworthy, however, that squatting-associated BP increase has been suspected to be a triggering factor for stroke in hypertensive patients from India (Chakrabarti et al., 2002).

\section{CONCLUSION}

Historically, squatting is known in the field of cardiology since many centuries when it was shown that this posture is able to alleviate symptoms of young patients with tetralogy of Fallot. Although the squatting test is less popular than the head-up tilt test, an extensive survey of the literature reveals many recent reports devoted to this posture test that represents the most powerful orthostatic stress compared to other manoeuvres. Squatting may be used as an active postural test capable to detect baroreflex haemodynamic dysregulation by measuring continuously BP and HR during the transition from standing to squatting (Table 1) and from squatting to standing (Table 2). This postural manoeuvre has been used to investigate baroreflex adaptation among patients with heart transplant (a model of heart denervation), 
with orthostatic hypotension (especially when resulting from autonomic failure), with neurocardiogenic vasovagal syncope and with diabetic CAN. Squatting may also be used as a therapeutic posture, not only in patients with tetralogy of Fallot, but more commonly in individuals prone to orthostatic hypotension or vasovagal syncope because squatting position is associated with a significant BP and cardiac output increase. In contrary, squatting position may be deleterious in hypertensive patients, especially when it is combined with a Valsalva manoeuvre. Thus, the standing to squatting and squatting to standing transitions can induce profound haemodynamic changes, especially in patients with autonomic failure, whose careful analysis may provide valuable information about baroreflex homeostasis. The squatting test may be considered as an interesting posture in both experimental and clinical situations.

\section{REFERENCES}

1. Apitz, C., Webb, G.D., Redington, A.N., 2009. Tetralogy of Fallot. Lancet 374, 14621471.

2. Brotmacher, L., 1957. Haemodynamic effects of squatting during recovery from exertion. Br. Heart J. 19, 567-573.

3. Chakrabarti, S.D., Ganguly, R., Chatterjee, S.K., Chakravarty, A., 2002. Is squatting a triggering factor for stroke in Indians? Acta Neurol. Scand. 105, 124-127.

4. Denq, J.C., Opfer-Gehrking, T.L., Giuliani, M., Felten, J., Convertino, V.A., Low, P.A., 1997. Efficacy of compression of different capacitance beds in the amelioration of orthostatic hypotension. Clin. Auton. Res. 7, 321-326.

5. Fedorowski, A., Stavenow, L., Hedblad, B., Berglund, G., Nilsson, P.M., Melander, O., 2010. Orthostatic hypotension predicts all-cause mortality and coronary events in middle-aged individuals (The Malmo Preventive Project). Eur. Heart J. 31, 85-91.

6. Freeman, R., 2008. Clinical practice. Neurogenic orthostatic hypotension. N. Engl. J. Med. 358, 615-624.

7. Grubb, B.P., Kosinski, D., 1997. Tilt table testing: concepts and limitations. Pacing Clin. Electrophysiol. 20, 781-787.

8. Guntheroth, W.G., Mortan, B.C., Mullins, G.L., Baum, D., 1968. Venous return with knee-chest position and squatting in tetralogy of Fallot. Am. Heart J. 75, 313-318. 
9. Hamilton, W.F., Winslow, J.A., Hamilton, W.F. Jr., 1950. Notes on a case of congenital heart disease with cyanotic episodes. J. Clin. Invest. 29, 20-27.

10. Hanson, P., Slane, P.R., Tueckert, P.A., Clark, S.V., 1995. Squatting revisited: comparison of haemodynamic responses in normal individuals and heart transplantation recipients. Br. Heart J. 74, 154-158.

11. Hunter, W., 1784. Three cases of malformation of the heart. Medical Observations and Inquiries by a Society of Physicians in London 6, 291.

12. Imholz, B.P., Settels, J.J., van der Meiracker, A.H., Wesseling, K.H., Wieling, W., 1990. Non-invasive continuous finger blood pressure measurement during orthostatic stress compared to intra-arterial pressure. Cardiovasc. Res. 24, 214-221.

13. Imholz, B.P., Wieling, W., van Montfrans, G.A., Wesseling, K.H., 1998. Fifteen years experience with finger arterial pressure monitoring: assessment of the technology. Cardiovasc. Res. 38, 605-616.

14. Krediet, C.T., Go-Schön, I.K., Kim, Y.S., Linzer, M., Van Lieshout, J.J., Wieling, W., 2007. Management of initial orthostatic hypotension: lower body muscle tensing attenuates the transient arterial blood pressure decrease upon standing from squatting. Clin. Physiol. (Lond.) 113, 401-407.

15. Krediet, C.T., Go-Schön, I.K., van Lieshout, J.J., Wieling, W., 2008. Optimizing squatting as a physical maneuver to prevent vasovagal syncope. Clin. Auton. Res. 18, 179-186.

16. Krediet, C.T., van Lieshout, J.J., Bogert, L.W., Immink, R.V., Kim, Y.S., Wieling, W., 2005a. Leg crossing, muscle tensing, squatting, and the crash position are effective against vasovagal reactions solely through increases in cardiac output. J. Appl. Physiol. 99, 1697-1703.

17. Krediet, C.T., Wilde, A.A., Halliwill, J.R., Wieling, W., 2005b. Syncope during exercise, documented with continuous blood pressure monitoring during ergometer testing. Clin. Auton. Res. 15, 59-62.

18. Kim, K.H., Cho, J.G., Lee, K.O., Seo, T.J., Shon, C.Y., Lim, S.Y., Yun, K.H., Sohn, I.S., Hong, Y.J., Park, H.W., Kim, J.H., Kim, W., Ahn, Y.K., Jeong, M.H., Park, J.C., Kang, J.C., 2005. Usefulness of physical maneuvers for prevention of vasovagal syncope. Circ. J. 69, 1084-1088.

19. Lahrmann, H., Cortelli, P., Hilz, M., Mathias, C.J., Struhal, W., Tassinari, M., 2006. EFNS guidelines on the diagnosis and management of orthostatic hypotension. Eur. J. Neurol. 13, 930-936. 
20. Li, Q., Zhang, J., Li, B., Wang, W., Liu, J., Zhu, H., Wang, H., Yu, S., Cui, Q., Sun, G., Wu, X., Yi, D., 2009. Pulse oxygen saturation measured in standing and squatting positions may be useful in evaluating tetralogy of Fallot. Heart Surg. Forum 12, E35E38.

21. Low, P.A., Singer, W., 2008. Management of neurogenic orthostatic hypotension: an update. Lancet Neurol. 7, 451-458.

22. Lurie, P.R., 1953. Postural effects in tetralogy of Fallot. Am. J. Med. 15, 297-306.

23. Madden, K.M., Tedder, G., Lockhart, C., Meneilly, G.S., 2008. Euglycemic hyperinsulinemia alters the response to orthostatic stress in older adults with type 2 diabetes. Diabetes Care 31, 2203-2208.

24. Marfella, R., Giugliano, D., Di Maro, G., Acampora, R., Giunta, R., D'Onofrio, F., 1994a. The squatting test : a useful tool to assess both parasympathetic and sympathetic involvement of the cardiovascular autonomic neuropathy in diabetes. Diabetes 43, 607-612.

25. Marfella, R., Salvatore, T., Giugliano, D., Di Maro, G., Giunta, R., Torella, R., Juchmes, J., Scheen, A., Lefèbvre, P.J., 1994b. Detection of early sympathetic cardiovascular neuropathy by squatting test in NIDDM. Diabetes Care 17, 149-151.

26. Maser, R.E., Mitchell, B.D., Vinik, A.I., Freeman, R., 2003. The association between cardiovascular autonomic neuropathy and mortality in individuals with diabetes: a meta-analysis. Diabetes Care 26, 1895-1901.

27. Medow, M.S., Stewart, J.M., Sanyal, S., Mumtaz, A., Sica, D., Frishman, W.H., 2008. Pathophysiology, diagnosis, and treatment of orthostatic hypotension and vasovagal syncope. Cardiol. Rev. 16, 4-20.

28. Morillo, C.A., Camacho, M.E., Wood, M.A., Gilligan, D.M., Ellenbogen, K.A., 1999. Diagnostic utility of mechanical, pharmacological and orthostatic stimulation of the carotid sinus in patients with unexplained syncope. J. Am. Coll. Cardiol. 34, 15871594.

29. Morillo, C.A., Eckberg, D.L., Ellenbogen, K.A., Beightol, L.A., Hoag, J.B., Tahvanainen, K.U., Kuusela, T.A., Diedrich, A.M., 1997. Vagal and sympathetic mechanisms in patients with orthostatic vasovagal syncope. Circulation 96, 25092513.

30. Murrell, C., Cotter, J.D., George, K, Shave, R., Wilson, L., Thomas, K., Williams, M.J., Lowe, T., Ainslie, P.N., 2009. Influence of age on syncope following prolonged 
exercise: differential responses but similar orthostatic intolerance. J. Physiol. 587, 5959-5969.

31. Nakagawa, M., Shinohara, T., Anan, F., Yufu, K., Takahashi, N., Okada, N., Hara, M., Yoshimatsu, H., Saikawa, T. , 2008. New squatting test indices are useful for assessing baroreflex sensitivity in diabetes mellitus. Diabetic Med. 25, 1309-1315.

32. Philips, J.C., Marchand, M., Scheen, A.J., 2008. Squatting amplifies pulse pressure increase according to duration of type 1 diabetes. Diabetes Care 31, 322-324.

33. Philips, J.C., Marchand, M., Scheen, A.J., 2009. Pulse pressure and cardiovascular autonomic neuropathy according to duration of type 1 diabetes. Diabetes Metab. Res. Rev. 25, 442-451.

34. Philips, J.C., Marchand, M., Scheen, A.J., 2010a. Changes in pulse pressure, heart rate and double product during squatting in type 1 diabetes according to age. Diabetic Med. 27, 753-761.

35. Philips, J.C., Marchand, M., Scheen, A.J., 2010b. Pulsatile stress in middle-aged patients with type 1 or type 2 diabetes compared to nondiabetic controls. Diabetes Care $33,2424-2429$.

36. Raj, S.R., 2010. Highlights in clinical autonomic neurosciences: orthostatic tachycardia and orthostatic hypotension. Auton. Neurosci. 154, 1-2.

37. Rickards, C.A., Newman, D.G., 2003. A comparative assessment of two techniques for investigating initial cardiovascular reflexes under acute orthostatic stress. Eur. J. Appl. Physiol. 90, 449-457.

38. Rossberg, F., Penaz, J., 1988. Initial cardiovascular response on change of posture from squatting to standing. Eur. J. Appl. Physiol. 57, 93-97.

39. Scheen, A.J., Juchmes, J., Pochet, Th., 1990. Non invasive, beat-to-beat, investigation of the effects of posture on arterial blood pressure in diabetic neuropathy. Diab. Metab. 16, 382-384.

40. Schutzman, J., Jaeger, F., Maloney, J., Fouad-Tarazi, F., 1994. Head-up tilt and hemodynamic changes during orthostatic hypotension in patients with supine hypertension. J. Am. Coll. Cardiol. 24, 454-461.

41. Somers, V.K., Abboud, F.M., 1996. Neurocardiogenic syncope. Adv. Intern. Med. 41, $399-435$.

42. Smit, A.A., Wieling, W., Fujimura, J., Denq, J.C., Opfer-Gehrking, T.L., Akarriou, M., Karemaker, J.M., Low, P.A., 2004. Use of lower abdominal compression to 
combat orthostatic hypotension in patients with autonomic dysfunction. Clin. Auton. Res. 14, 167-175.

43. Smith, J.J., Porth, C.M., Erickson, M., 1994. Hemodynamic response to the upright posture. J. Clin. Pharmacol. 34, 375-386.

44. Stewart, J.M., 2002. Pooling in chronic orthostatic intolerance: arterial vasoconstrictive but not venous compliance defects. Circulation 105, 2274-2281.

45. Stewart, J.M., Weldon, A., 2003. Contrasting neurovascular findings in chronic orthostatic intolerance and neurocardiogenic syncope. Clin. Sci. 104, 329-340.

46. Titianova, E., Karakaneva, S., Velcheva, I., 1997. Orthostatic dysregulation in progressive autonomic failure--a transcranial Doppler sonography monitoring. J. Neurol. Sci. 146, 87-91.

47. Tutaj, M., Marthol, H., Berlin, D., Brown, C.M., Axelrod, F.B., Hilz, M.J., 2006. Effect of physical countermaneuvers on orthostatic hypotension in familial dysautonomia. J. Neurol. 253, 65-72.

48. van Lieshout, J.J., ten Harkel, A.D., Wieling, W., 1992. Physical manoeuvres for combating orthostatic dizziness in autonomic failure. Lancet 339, 897-898.

49. Weimer, L.H., 2010. Autonomic testing: common techniques and clinical applications. Neurologist 16, 215-222.

50. Wieling, W., Colman, N., Krediet, C.T., Freeman, R., 2004. Nonpharmacological treatment of reflex syncope. Clin. Auton. Res. 14 (Suppl 1), 62-70.

51. Wieling, W., Krediet, C.T., van Dijk, N., Linzer, M., Tschakovsky, M.E., 2007. Initial orthostatic hypotension: review of a forgotten condition. Clin. Sci. (Lond.) 112, 157165.

52. Wieling, W., van Lieshout, J.J., van Leeuwen, A.M., 1993. Physical manoeuvres that reduce postural hypotension in autonomic failure. Clin. Auton. Res. 3, 57-65.

Conflict of interest : none declared

Acknowledgements : The authors thank Monique Marchand for her valuable help in the illustration of this paper. 
Table 1 : Summary of haemodynamic changes occurring in squatting position (versus standing) in various pathologies.

\begin{tabular}{|c|c|c|}
\hline Disease & Reference & Haemodynamic changes \\
\hline Tetralogy of Fallot & $\begin{array}{l}\text { Guntheroth et al., } 1968 \\
\text { Li et al., } 2009\end{array}$ & $\begin{array}{l}\uparrow \mathrm{BP}, \uparrow \text { arterial } \mathrm{O}_{2} \text { saturation } \\
\uparrow \text { pulse } \mathrm{O}_{2} \text { saturation }\end{array}$ \\
\hline Heart transplant & Hanson et al., 1995 & $\begin{array}{l}\uparrow \mathrm{BP}, \uparrow \mathrm{SV}, \text { no } \uparrow \mathrm{HR}, \\
\uparrow \mathrm{PAR} \text { (less than in controls) }\end{array}$ \\
\hline $\begin{array}{l}\text { Dysautonomia with } \\
\text { orthostatic hypotension }\end{array}$ & $\begin{array}{l}\text { Wieling et al., } 1993 \\
\text { Van Lieshout et al., } 1992 \\
\text { Titianova et al., } 1997 \\
\text { Tutaj et al., } 2006\end{array}$ & $\begin{array}{l}\uparrow \mathrm{BP} \\
\uparrow \uparrow \mathrm{BP} \\
\uparrow \uparrow \mathrm{BP}, \uparrow \text { cerebral blood flow velocity } \\
\uparrow \uparrow \mathrm{BP}, \uparrow \mathrm{CO}, \uparrow \mathrm{PAR}, \approx \mathrm{HR}\end{array}$ \\
\hline $\begin{array}{l}\text { Neurocardiogenic } \\
\text { syncope }\end{array}$ & $\begin{array}{l}\text { Kim et al., } 2005 \\
\text { Krediet et al., } 2005\end{array}$ & $\begin{array}{l}\uparrow \mathrm{BP}, \text { syncope abortion } \\
\text { Prevention of exercise-related } \\
\text { vasovagal syncope }\end{array}$ \\
\hline Arterial hypertension & Chakrabarti et al., 2002b & Exaggerated $\uparrow \mathrm{BP}$ \\
\hline $\begin{array}{l}\text { Diabetic cardiovascular } \\
\text { autonomic neuropathy }\end{array}$ & $\begin{array}{l}\text { Marfella et al., 1994a } \\
\text { Nakagawa et al., } 2008 \\
\text { Philips et al., } 2009\end{array}$ & $\begin{array}{l}\text { Reduced bradycardia (SqTv index) } \\
\text { Reduced bradycardia (Delta HRSq) } \\
\text { Reduced bradycardia } \\
\text { Increased BP and PP }\end{array}$ \\
\hline
\end{tabular}

BP : blood pressure. $\mathrm{O}_{2}$ : oxygen. $\mathrm{SV}$ : stroke volume. PAR : peripheral arterial resistance. $\mathrm{CO}$ : cardiac output. HR : heart rate. 
Table 2 : Summary of haemodynamic changes occurring in post-squatting standing position in various pathologies.

\begin{tabular}{|l|l|l|}
\hline Disease & Reference & Haemodynamic changes \\
\hline $\begin{array}{l}\text { Dysautonomia with } \\
\text { orthostatic hypotension }\end{array}$ & Titianova et al., 1997 & $\begin{array}{l}\downarrow \text { BP, no } \uparrow \text { HR, } \\
\downarrow \text { cerebral blood flow velocity }\end{array}$ \\
\hline $\begin{array}{l}\text { Neurocardiogenic } \\
\text { syncope }\end{array}$ & Krediet et al., 2007, 2008 & $\begin{array}{l}\text { Less } \downarrow \text { BP with lower body skeletal } \\
\text { muscle tensing }\end{array}$ \\
\hline Diabetic cardiovascular & $\begin{array}{l}\text { Marfella et al., 1994a } \\
\text { Marfella et al., 1994b } \\
\text { Nakagawa et al., 2008 }\end{array}$ & $\begin{array}{l}\text { Reduced tachycardia (SqTs index) } \\
\text { Greater } \downarrow \text { BP versus controls } \\
\text { Reduced tachycardia (delta HRSt) } \\
\text { Reduced baroreflex sensitivity (BRS) } \\
\text { Reduced tachycardia } \\
\text { Reduced baroreflex gain } \\
\text { Delayed BP recovery }\end{array}$ \\
\hline
\end{tabular}

BP : blood pressure. HR : heart rate. 


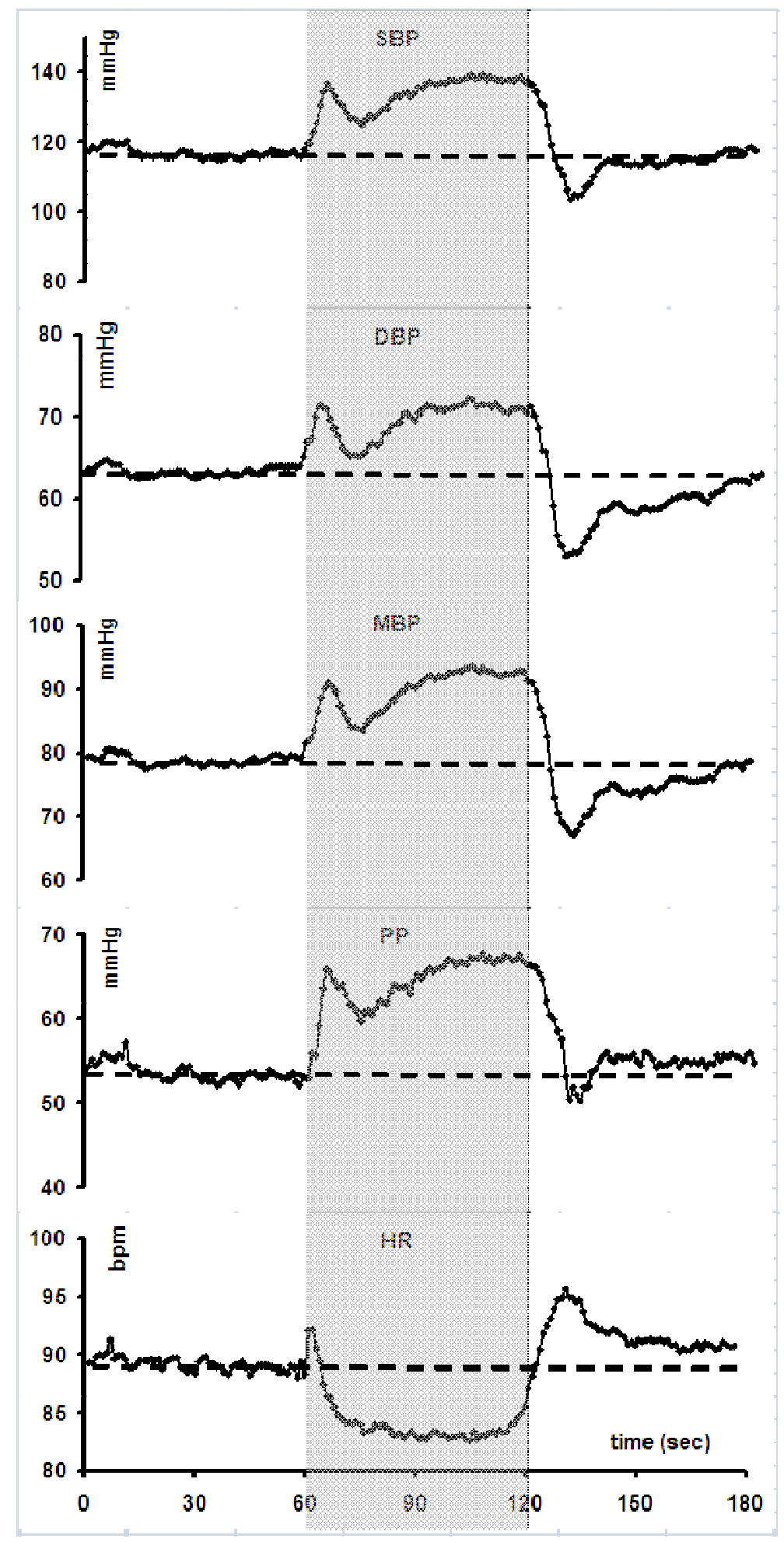

Figure 1 : Mean changes in systolic (SBP), diastolic (DBP), and mean blood pressure (MBP), pulse pressure (PP) and heart rate (HR) measured continuously with a Finapres ${ }^{\circledR}$ during a standing-squatting (grey zone)-standing test in 40 healthy subjects (20 men, 20 women; mean age : 50 years,; mean body mass index : $22.2 \mathrm{~kg} / \mathrm{m}^{2}$ ). Please note the two-phase changes during squatting and the biphasic initial changes after standing up. 


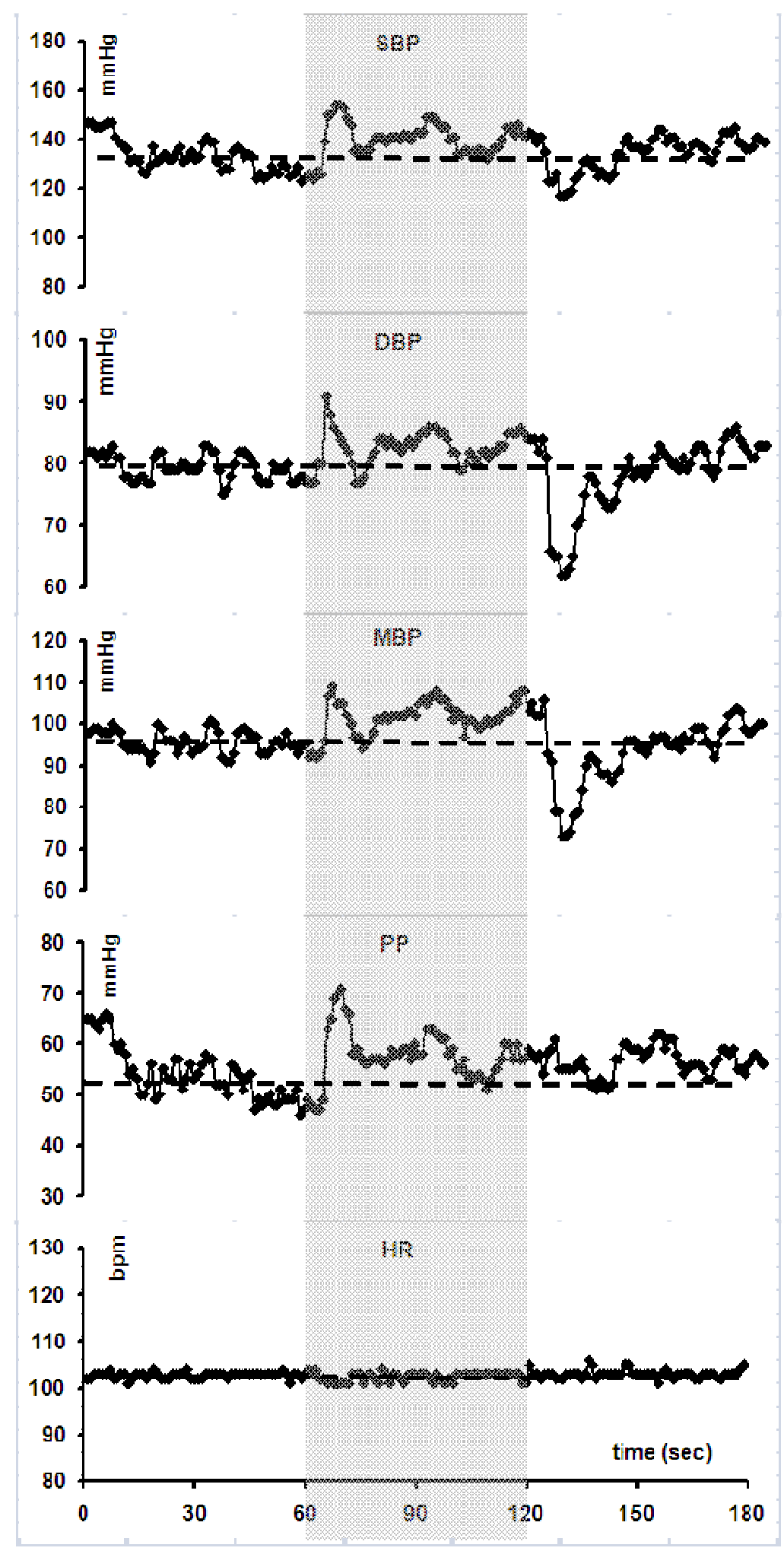

Figure 2 : Changes in systolic (SBP), diastolic (DBP), and mean blood pressure (MBP), pulse pressure (PP) and heart rate (HR) measured continuously with a Finapres ${ }^{\circledR}$ during a standingsquatting (grey zone)-standing test in a patient with heart transplant. Please note the fixed tachycardia but the almost normal changes in BP (compared to figure 1). 


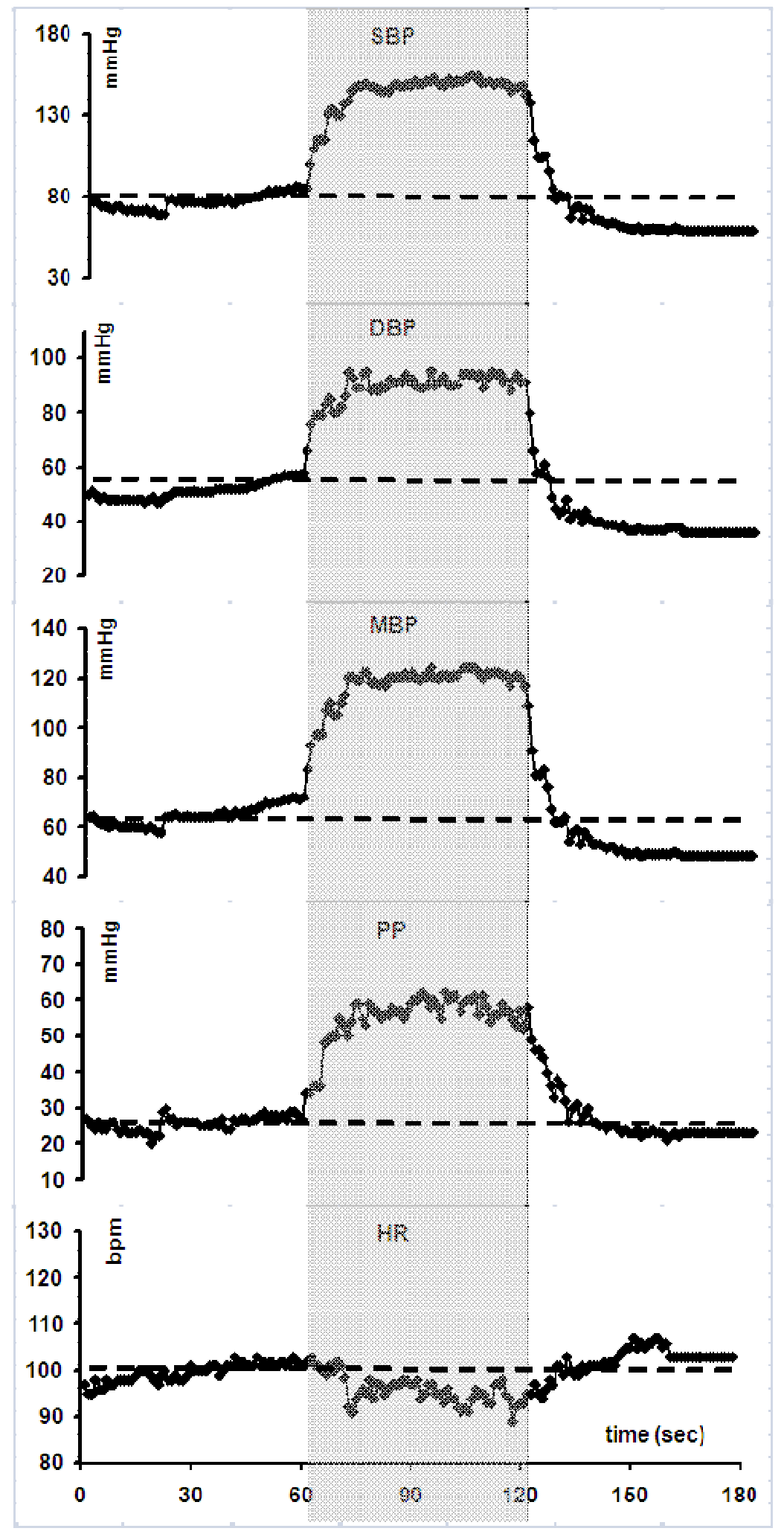

Figure 3 : Changes in systolic (SBP), diastolic (DBP), and mean blood pressure (MBP), pulse pressure (PP) and heart rate (HR) measured continuously with a Finapres ${ }^{\circledR}$ during a standingsquatting (grey zone)standing test in a patient with dysautonomia and severe orthostatic hypotension (orthostatic intolerance). Please note the marked elevation of BP and PP while squatting and the abrupt drop after standing, without major changes in HR.. 


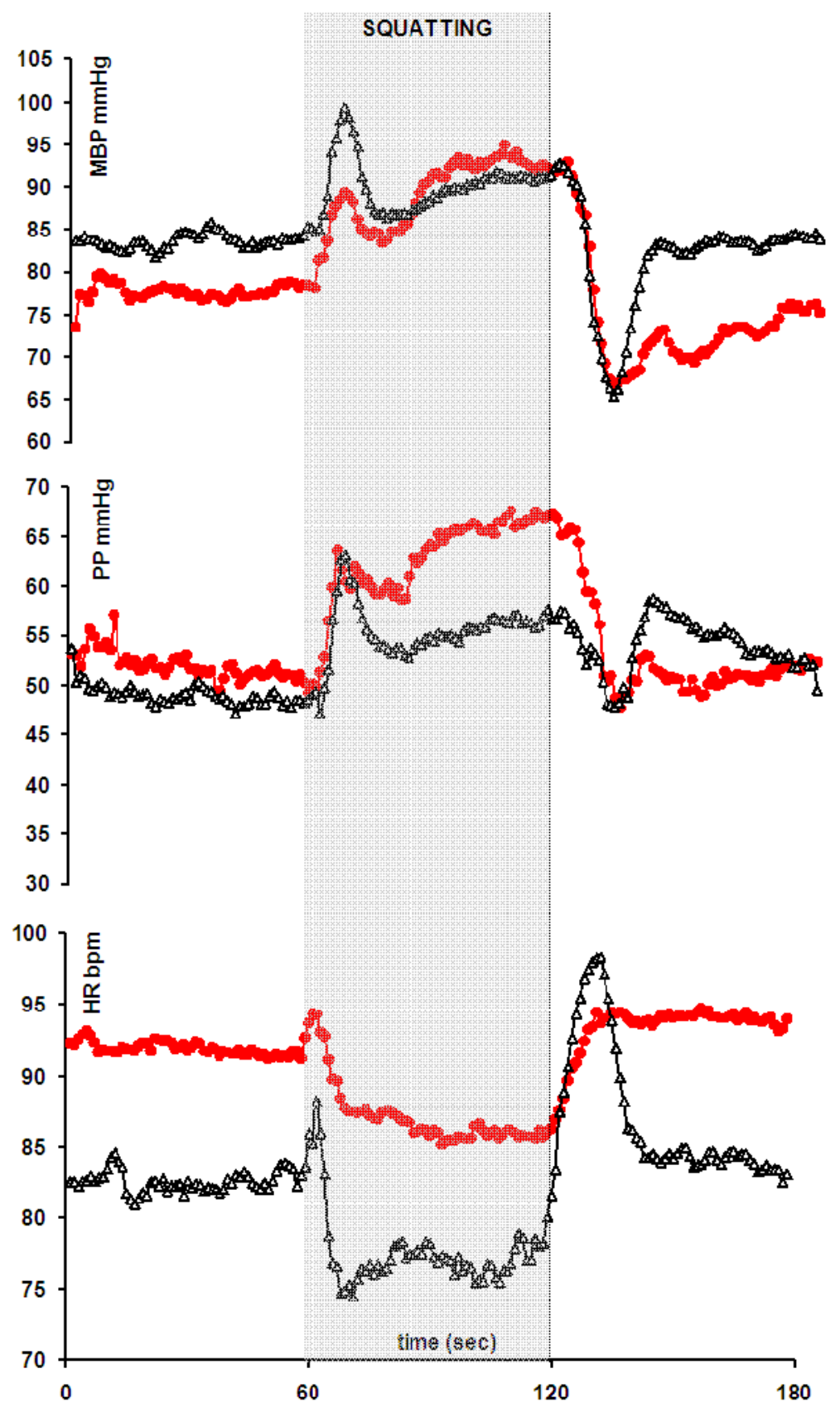

Figure 4 : Changes in mean arterial blood pressure (MBP), pulse pressure (PP) and heart rate (HR) during a posture test [ 1 min standing -1 min squatting (grey zone) -1 min standing] in 20 patients with type 1 diabetes (T1DM) and low RR E/I ratio indicative of cardiovascular autonomic neuropathy (CAN) (full circles) versus 40 non-diabetic subjects (controls) (open triangles) matched for age, sex and body mass index. 